\title{
Alcohol consumption in relation to cardiovascular and non-cardiovascular mortality in an elderly male Chinese population
}

Xiao-Fei Ye ${ }^{1}$, Chao-Ying Miao', Wei Zhang ${ }^{2}$, Chang-Sheng Sheng ${ }^{2}$, Qi-Fang Huang ${ }^{2}$ and Ji-Guang Wang ${ }^{1,2^{*}}$

\begin{abstract}
Background: We investigated the association of alcohol consumption with cardiovascular and non-cardiovascular mortality in elderly Chinese men.

Methods: Our participants were recruited from residents living in a suburban town of Shanghai ( $\geq 60$ years of age, $n=1702$ ). Alcohol intake was classified as non-drinkers, past drinkers (stopped drinking for $\geq 12$ months), and current light-to-moderate ( 1 to $299 \mathrm{~g} /$ week) and heavy drinkers ( $\geq 300 \mathrm{~g} /$ week). Alcoholic beverages were classified as beer/wine, rice aperitif and liquor/mix drinking.

Results: During 5.9 years (median) of follow-up, all-cause, cardiovascular and non-cardiovascular deaths occurred in 211, 98 and 113 participants, respectively. The corresponding incidence rates were 23.6/1000, 10.9/1000 and 12.6/ 1000 person-years, respectively. Both before and after adjustment for confounding factors, compared with nondrinkers $(n=843)$, past drinkers $(n=241)$, but not the current light-to-moderate $(n=241)$ or heavy drinkers $(n=$ 377), had a higher risk of all-cause (adjusted hazard ratio [HR] 1.90, 95\% confidence interval [CI] 1.35-2.68, $P=$ 0.0003 ) and non-cardiovascular mortality (HR 2.46, 95\% Cl 1.55-3.91, $P=0.0001)$. Similar trends were observed for cardiovascular mortality (HR 1.44, 95\% Cl 0.85-2.44, $P=0.18$ ). In similar unadjusted and adjusted analyses, compared with the current beer/wine drinkers $(n=203)$, liquor/mix drinkers $(n=142)$, but not aperitif drinkers $(n=273)$, had a significantly higher risk of all-cause (HR 3.07,95\% Cl 1.39-6.79, $P=0.006)$, and cardiovascular mortality (HR 10.49, $95 \% \mathrm{Cl} 2.00-55.22, P=0.006)$. Similar trends were observed for non-cardiovascular mortality (HR 1.94, 95\% Cl $0.73-$ $5.16, P=0.18)$.
\end{abstract}

Conclusions: Our study showed risks of mortality associated with past drinking and liquor drinking in the elderly Chinese men.

Keywords: Alcohol consumption, Mortality, All-cause mortality, Cardiovascular mortality

\footnotetext{
* Correspondence: jiguangwang@aim.com

'School of Public Health, Shanghai Jiao Tong University School of Medicine, Shanghai, China

${ }^{2}$ Department of Cardiovascular Medicine, The Shanghai Institute of Hypertension, Ruijin Hospital, Shanghai Jiao Tong University School of Medicine, Shanghai, China
}

(c) The Author(s). 2021 Open Access This article is licensed under a Creative Commons Attribution 4.0 International License, which permits use, sharing, adaptation, distribution and reproduction in any medium or format, as long as you give appropriate credit to the original author(s) and the source, provide a link to the Creative Commons licence, and indicate if changes were made. The images or other third party material in this article are included in the article's Creative Commons licence, unless indicated otherwise in a credit line to the material. If material is not included in the article's Creative Commons licence and your intended use is not permitted by statutory regulation or exceeds the permitted use, you will need to obtain permission directly from the copyright holder. To view a copy of this licence, visit http://creativecommons.org/licenses/by/4.0/ The Creative Commons Public Domain Dedication waiver (http://creativecommons.org/publicdomain/zero/1.0/) applies to the data made available in this article, unless otherwise stated in a credit line to the data. 


\section{Introduction}

There is consensus that alcohol intake at any quantity and of any class is detrimental [1]. Indeed, according to the Global Burden of Disease (GDB) study, alcohol intake was associated with 5.3, 3.3 and $4.1 \%$ of increased all-cause and cardiovascular mortality and cancers worldwide, respectively. The corresponding increases in all-cause mortality and cancers in the Chinese population were 4.1 and $6.2 \%$, respectively [2, 3]. However, for now and probably for a long while in the future, alcohol drinking will continue as a major lifestyle factor in many populations. In China, alcohol intake is a habit mainly in men and rarely in women, and alcoholic beverages include beer and wine as in other populations and rice aperitif and white spirit typically in the Chinese population [4]. In addition, although regular drinking is prevalent, binge drinking is the predominant pattern in China, especially in liquor drinkers. Indeed, according to a recent national survey, $29.8 \%$ of male drinkers drank heavily once a week or more and $83.6 \%$ of them drank heavily occasionally [5].

We believe that liquor drinking, especially the binge drinking pattern, is particularly deleterious to health. One of the difficulties in drinking studies is that drinkers may stop drinking when they become unhealthy or have a severe disease diagnosed. Under such circumstances, the risk of drinking would be underestimated. We hypothesize that in the elderly past drinkers and liquor drinkers particularly have increased risks of cardiovascular and non-cardiovascular diseases. Such research requires a study population with a high proportion of drinkers including both past and current drinkers. We recently conducted an elderly population-based study in Shanghai, China. The proportion of alcohol intake was high in men [6-9]. In the present study, we investigated the association between the quantity and type of alcoholic beverage consumption and the risk of cardiovascular and non-cardiovascular mortality in this elderly male Chinese population.

\section{Methods}

\section{Study population}

Our study was conducted in the framework of the Chronic Disease Detection and Management in the Elderly ( $\geq 60$ years of age) Program supported by the municipal government of Shanghai, as described previously [6-9]. In a newly urbanized suburban town $30 \mathrm{~km}$ from the city center, we invited all residents of at least 60 years of age to participate in comprehensive examinations of cardiovascular disease and risk. All study participants were previously doing farming in their villages, and retired when they participated in the study. The Ethics Committee of Ruijin Hospital, Shanghai Jiao Tong University School of Medicine, approved the study protocol. All subjects provided written informed consent.

A total of 3997 subjects (participation rate, 90\%) were enrolled in the period from 2006 to 2011 and followed up for vital status and cause of death till June 30, 2013. We excluded 2212 women because of low drinking rate (1.3\%, $n=29)$, and further excluded 85 men from the present analysis because information on alcohol intake was not recorded. Thus, the number of participants included in the present analysis was 1702 .

\section{Field work}

The methods for field work had been described previously [6-9]. One experienced physician measured each participant's blood pressure three times consecutively on the nondominant arm using a validated Omron 7051 oscillometric blood pressure monitor (Omron Healthcare, Kyoto, Japan) after the subjects had rested for at least $5 \mathrm{~min}$ in the sitting position. These three blood pressure readings were averaged for analysis. Hypertension was defined as a sitting blood pressure of at least $140 \mathrm{mmHg}$ systolic or $90 \mathrm{mmHg}$ diastolic or as the use of antihypertensive drugs.

A trained technician performed anthropometric measurements, including body height and body weight. Body mass index was calculated as the body weight in kilograms divided by the body height in meters squared. Abdominal obesity was defined as a waist circumference $\geq$ $90 \mathrm{~cm}$.

Venous blood samples were drawn after overnight fasting for the measurement of plasma glucose and serum total cholesterol and triglycerides. Diabetes mellitus was defined as a plasma glucose level of at least 7.0 $\mathrm{mmol} / \mathrm{L}$ while fasting or $11.1 \mathrm{mmol} / \mathrm{L}$ at any time or as the use of antidiabetic agents.

\section{Alcohol consumption}

A standardized questionnaire was administered by a physician to collect information on medical history, alcohol consumption, smoking habits and the use of medications. Alcohol consumption was assessed for the quantity and frequency of various alcoholic beverages consumed during the past 12 months. Participants were inquired about the alcohol use, type of alcoholic beverages (beer, wine, aperitif or liquor), and frequency and quantity of consumption per week. Beers $(4-6 \% \mathrm{v} / \mathrm{v}$ ethanol) and wines $(10-12 \% \mathrm{v} / \mathrm{v}$ ethanol) are usually in bottles of $750 \mathrm{ml}$. Yellow or white rice aperitifs (15-18\% $\mathrm{v} / \mathrm{v}$ ethanol) and hard liquors $(52-53 \% \mathrm{v} / \mathrm{v}$ ethanol) are in bottles of $500 \mathrm{ml}$. We estimated that one bottle of beer, wine, aperitif, and liquor on average contained 30, 90, 90, and $200 \mathrm{~g}$ of ethanol, respectively [10]. Average alcohol consumption (in grams per week) was computed by multiplying frequency and amount of the alcoholic 
beverages consumed. Individuals were classified as nondrinkers, past drinkers (stopped drinking for at least 12 months), and current light-to-moderate (1 to $299 \mathrm{~g} /$ week) and heavy drinkers ( $\geq 300 \mathrm{~g} /$ week) $[10,11]$. Because beer and wine are considered similarly as low volume alcohol in China, we classified beer and wine drinkers as a single group in the analysis according to the type of beverages.

\section{Follow-up}

Information on vital status and the cause of death was obtained from the official death certificate, with further confirmation by the local Community Health Center and family members of the deceased people, as described previously [6-9]. The International Classification of Diseases Ninth Revision (ICD-9) was used to classify the cause of death. Cardiovascular mortality included deaths attributable to stroke, myocardial infarction, and other cardiovascular diseases (ICD-9, 390.0-459.9).

\section{Statistical methods}

For database management and statistical analysis, we used SAS software (version 9.4; SAS Institute, Cary, NC, USA). Means were compared by the analysis of variance (ANOVA) with the Student-Newman-Keuls test for a posteriori between-group contrast at a significance level set at $5 \%$. Proportions were compared by the Chi-square test. Continuous measurements with a skewed distribution were expressed as median with interquartile range and were analyzed using the non-parametric KruskalWallis test. The log-rank test was used to compare the cumulative incidence of mortality between groups with the Kaplan-Meier survival function to show the time to death. Multiple Cox regression analysis was performed to compute hazard ratios (HRs) and 95\% confidence intervals (CIs) for the association between alcohol intake and mortality. Proportional hazards assumption was checked by assessing the Schoenfeld residuals [12]. A two-tailed $P$ value less than 0.05 was considered statistically significant.

\section{Results}

\section{Characteristics of the study participants}

The 1702 male study participants included 843 (49.5\%) non-drinkers, 241 (14.2\%) past drinkers, and 618 (36.3\%) current light-to-moderate $(n=241,14.2 \%)$ and heavy drinkers $(n=377,22.1 \%)$. In current drinkers, the number of beer/wine, aperitif and liquor/mix drinkers was 203 (32.8\%), 273 (44.2\%), and 142 (23.0\%), respectively.

The study participants differed significantly $(P \leq$ $0.02)$ across the alcohol consumption categories in most of the baseline characteristics, such as age (67.4 to 69.3 years), systolic/diastolic blood pressure (135.7 to $142.9 / 80.2$ to $83.9 \mathrm{mmHg}$ ), current smoking (45.2 to $67.9 \%$ ), prevalence of hypertension (56.9 to $66.0 \%$ ), and the use of antihypertensive drugs (32.6 to 54.4\%). Nonetheless, they had similar $(P \geq 0.12)$ body-mass index $\left(23.5 \mathrm{~kg} / \mathrm{m}^{2}\right)$, waist circumference $(81.1 \mathrm{~cm})$, prevalence of central obesity (19.6\%), pulse rate (74.6 beats $/ \mathrm{min})$, serum total cholesterol $(5.45 \mathrm{mmol} / \mathrm{L})$ and triglycerides $(1.55 \mathrm{mmol} / \mathrm{L})$, and the prevalence of diabetes mellitus (7.6\%, Table 1$)$.

Table 1 Characteristics of the study participants by alcohol intake $(n=1702)$

\begin{tabular}{|c|c|c|c|c|}
\hline \multirow[t]{2}{*}{ Characteristics } & \multirow{2}{*}{$\begin{array}{l}\text { Non-drinkers } \\
(n=843)\end{array}$} & \multirow{2}{*}{$\begin{array}{l}\text { Past drinkers } \\
(n=241)\end{array}$} & \multicolumn{2}{|c|}{ Current drinkers $(n=618)$} \\
\hline & & & $\begin{array}{l}\text { Light-to-moderate } \\
(n=241)\end{array}$ & $\begin{array}{l}\text { Heavy } \\
(n=377)\end{array}$ \\
\hline Age, years & $69.2 \pm 7.4$ & $69.3 \pm 7.0$ & $67.8 \pm 7.0^{*}$ & $67.4 \pm 6.6^{*}$ \\
\hline Body mass index, $\mathrm{kg} / \mathrm{m}^{2}$ & $23.4 \pm 3.5$ & $23.5 \pm 3.6$ & $23.4 \pm 3.1$ & $23.8 \pm 3.5$ \\
\hline Waist circumference, $\mathrm{cm}$ & $80.5 \pm 9.4$ & $81.2 \pm 9.8$ & $81.4 \pm 9.7$ & $81.9 \pm 10.0$ \\
\hline Central obesity, n (\%) & $150(17.8)$ & $48(19.9)$ & $45(18.7)$ & $88(23.3)^{*}$ \\
\hline Systolic blood pressure, mmHg & $136.7 \pm 19.6$ & $135.7 \pm 19.6$ & $138.7 \pm 19.4$ & $142.9 \pm 19.8^{*}$ \\
\hline Diastolic blood pressure, $\mathrm{mmHg}$ & $80.5 \pm 10.8$ & $80.2 \pm 10.5$ & $82.2 \pm 11.2$ & $83.9 \pm 11.0^{*}$ \\
\hline Pulse rate, beats/min & $74.9 \pm 11.8$ & $74.6 \pm 12.4$ & $74.3 \pm 12.1$ & $74.0 \pm 11.8$ \\
\hline Fasting plasma glucose, mmol/l & $5.24 \pm 1.09$ & $5.31 \pm 1.09$ & $5.19 \pm 0.74$ & $5.36 \pm 1.15$ \\
\hline Serum total cholesterol, mmol// & $5.38 \pm 1.42$ & $5.52 \pm 1.42$ & $5.47 \pm 1.35$ & $5.55 \pm 1.46$ \\
\hline Serum triglycerides, mmol/l & $1.55(1.17-1.70)$ & $1.56(1.16-1.72)$ & $1.55(1.10-1.72)$ & $1.58(1.14-1.83)$ \\
\hline Current smoking, n (\%) & $413(49.0)$ & $109(45.2)$ & $146(60.6)^{*}$ & $256(67.9)^{*}$ \\
\hline Hypertension, n (\%) & $480(56.9)$ & $159(66.0)^{*}$ & $154(63.9)^{*}$ & $239(63.4)^{*}$ \\
\hline Use of antihypertensive drugs, n (\%) & $318(37.7)$ & $131(54.4)^{*}$ & $90(37.3)$ & $123(32.6)^{*}$ \\
\hline Diabetes mellitus, n (\%) & $67(8.0)$ & $22(9.1)$ & $12(5.0)$ & $29(7.7)$ \\
\hline
\end{tabular}

Values are mean \pm standard deviations, median (interquartile range) or number of participants (\% of column total) ${ }^{*} P \leq 0.05$ vs. non-drinkers 


\section{Alcohol intake and mortality}

During a median follow-up of 5.9 years (interquartile range, 4.9-6.8 years), the cumulated number of personyears was 8955, and all-cause, cardiovascular and noncardiovascular deaths occurred in 211, 98 and 113 subjects, respectively. The corresponding incidence rates were $23.6 / 1000,10.9 / 1000$ and $12.6 / 1000$ person-years, respectively.

Kaplan-Meier survival analyses showed a significant difference in the incidence of total, cardiovascular and non-cardiovascular mortality between non-drinkers, past drinkers and current light-to-moderate and heavy drinkers, with the highest incidence in past drinkers (log-rank test, $P \leq 0.009$, Fig. 1$)$. After adjustment for age, body-mass index, current smoking, serum total cholesterol and triglycerides, fasting plasma glucose, and the prevalence of hypertension and diabetes mellitus, compared with non-drinkers, past drinkers, but not light-to-moderate or heavy drinkers $(P \geq 0.32)$, had a significantly higher risk of total (HR 1.90, 95\% CI 1.352.68, $P=0.0003)$ and non-cardiovascular mortality (HR $2.46,95 \%$ CI 1.55-3.91, $P=0.0001$, Table 2). The risk of cardiovascular mortality was highest in past drinkers and lowest in heavy drinkers. Statistical significance relative to non-drinkers, however, was not achieved in either group $(P \geq 0.07)$.

\section{Alcoholic beverages and mortality}

Further analyses in current drinkers showed significant differences in the incidence of total and cardiovascular mortality between non-drinkers and current beer/wine, aperitif, and liquor/mix drinkers, with the highest incidence in liquor/mix drinkers and lowest incidence in beer/wine drinkers (log-rank test, $P=0.01$, Fig. 2). Similar trends were observed for non-cardiovascular mortality, though statistical significance was not achieved $(P=0.38)$. After adjustment for total alcohol consumption and above-mentioned confounding factors, liquor/mix drinkers, but not beer/wine or aperitif drinkers, had a significantly higher risk of cardiovascular mortality (HR 3.23, 95\% CI 1.24-8.39, $P=0.02$ ) than non-drinkers (Table 3).

With similar adjustments applied as above, compared with the current beer/wine drinkers, liquor/mix drinkers had a significantly higher risk of all-cause (HR 3.07, 95\% CI $1.39-6.79, P=0.006)$ and cardiovascular mortality (HR 10.49, 95\% CI 2.00-55.22, $P=0.006$ ). Similar trends were observed for non-cardiovascular mortality (HR 1.94, 95\% CI 0.73-5.16, $P=0.18$ ).

\section{Discussion}

The key finding of our study was that past drinkers had a higher risk of all-cause and non-cardiovascular mortality. With regard to the alcoholic beverages, liquor/mix

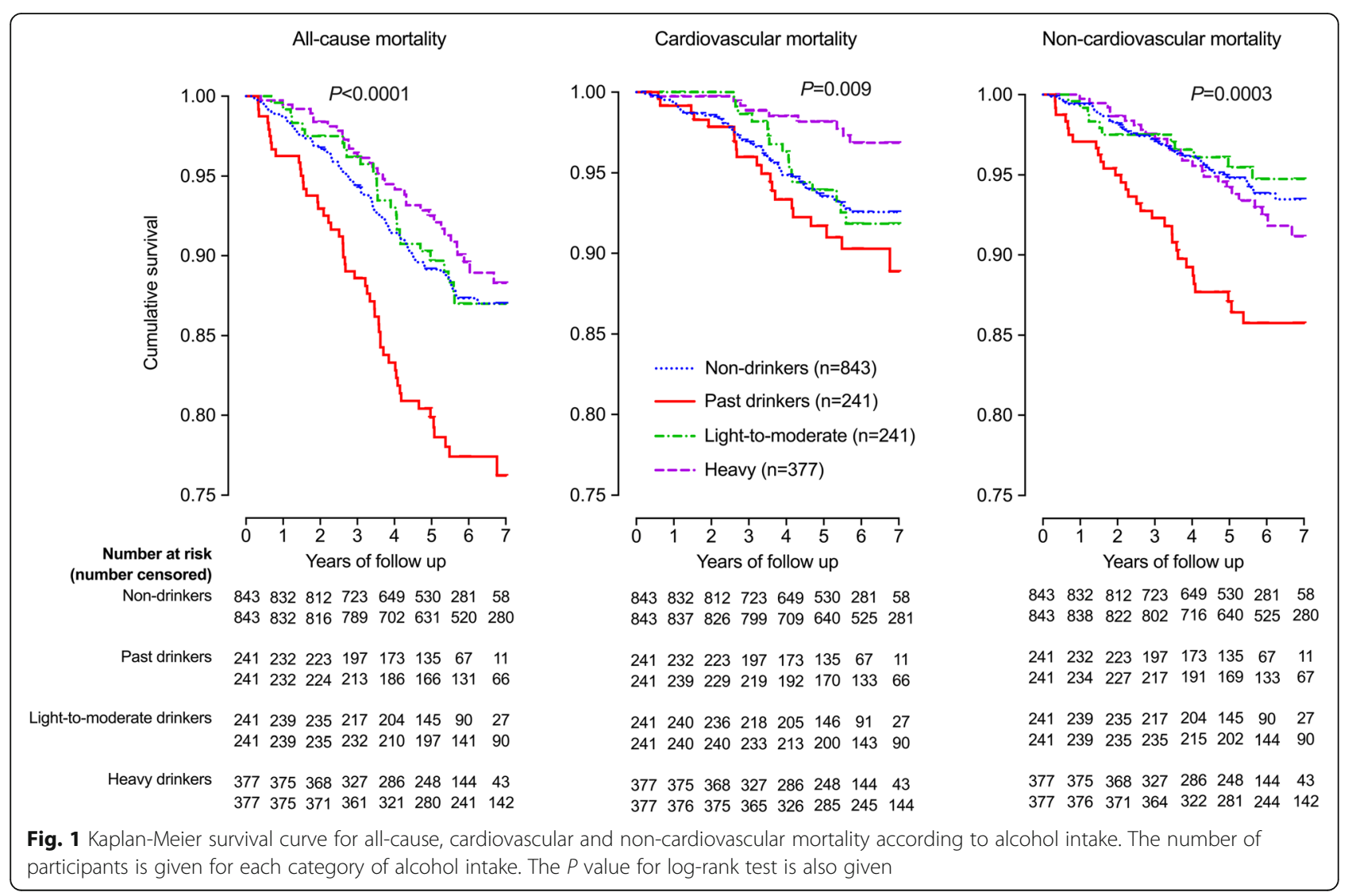


Table 2 All-cause, cardiovascular and non-cardiovascular mortality in relation to alcohol intake

\begin{tabular}{|c|c|c|c|c|}
\hline & \multirow{2}{*}{$\begin{array}{l}\text { Non- } \\
\text { drinkers }\end{array}$} & \multirow[t]{2}{*}{ Past drinkers } & \multicolumn{2}{|l|}{ Current drinkers } \\
\hline & & & Light-to-moderate & Heavy \\
\hline Number of participants & 843 & 241 & 241 & 377 \\
\hline Number of person-years & 4429 & 1201 & 1311 & 2014 \\
\hline \multicolumn{5}{|l|}{ All-cause mortality } \\
\hline Number of deaths & 100 & 50 & 27 & 34 \\
\hline Rate per 1000 person-years & 22.6 & 41.6 & 20.6 & 16.9 \\
\hline Age-adjusted HR (95\% Cl) & 1 & $1.89(1.35-2.66)$ & $1.07(0.70-1.63)$ & $0.92(0.62-1.36)$ \\
\hline Multivariate-adjusted HR (95\% Cl) & 1 & $1.90(1.35-2.68)$ & $1.09(0.71-1.67)$ & $0.89(0.60-1.34)$ \\
\hline \multicolumn{5}{|l|}{ Cardiovascular mortality } \\
\hline Number of deaths & 53 & 20 & 16 & 9 \\
\hline Rate per 1000 person-years & 12.0 & 16.7 & 12.2 & 4.5 \\
\hline Age-adjusted HR (95\% Cl) & 1 & $1.50(0.90-2.51)$ & $1.25(0.72-2.19)$ & $0.51(0.25-1.02)$ \\
\hline Multivariate-adjusted HR (95\% Cl) & 1 & $1.44(0.85-2.44)$ & $1.17(0.66-2.07)$ & $0.51(0.25-1.05)$ \\
\hline \multicolumn{5}{|l|}{ Non-cardiovascular mortality } \\
\hline Number of deaths & 47 & 30 & 11 & 25 \\
\hline Rate per 1000 person-years & 10.6 & 25.0 & 8.4 & 12.4 \\
\hline Age-adjusted HR (95\% Cl) & 1 & $2.36(1.50-3.74)$ & $0.88(0.45-1.69)$ & $1.33(0.81-2.16)$ \\
\hline Multivariate-adjusted HR (95\% Cl) & 1 & $2.46(1.55-3.91)$ & $0.92(0.48-1.79)$ & $1.29(0.78-2.13)$ \\
\hline
\end{tabular}

The multivariate analyses were adjusted for age, body mass index, current smoking, serum total cholesterol and triglycerides, fasting plasma glucose and the prevalence of hypertension and diabetes mellitus at baseline

$\mathrm{Cl}$ : confidence interval; HR: hazard ratio

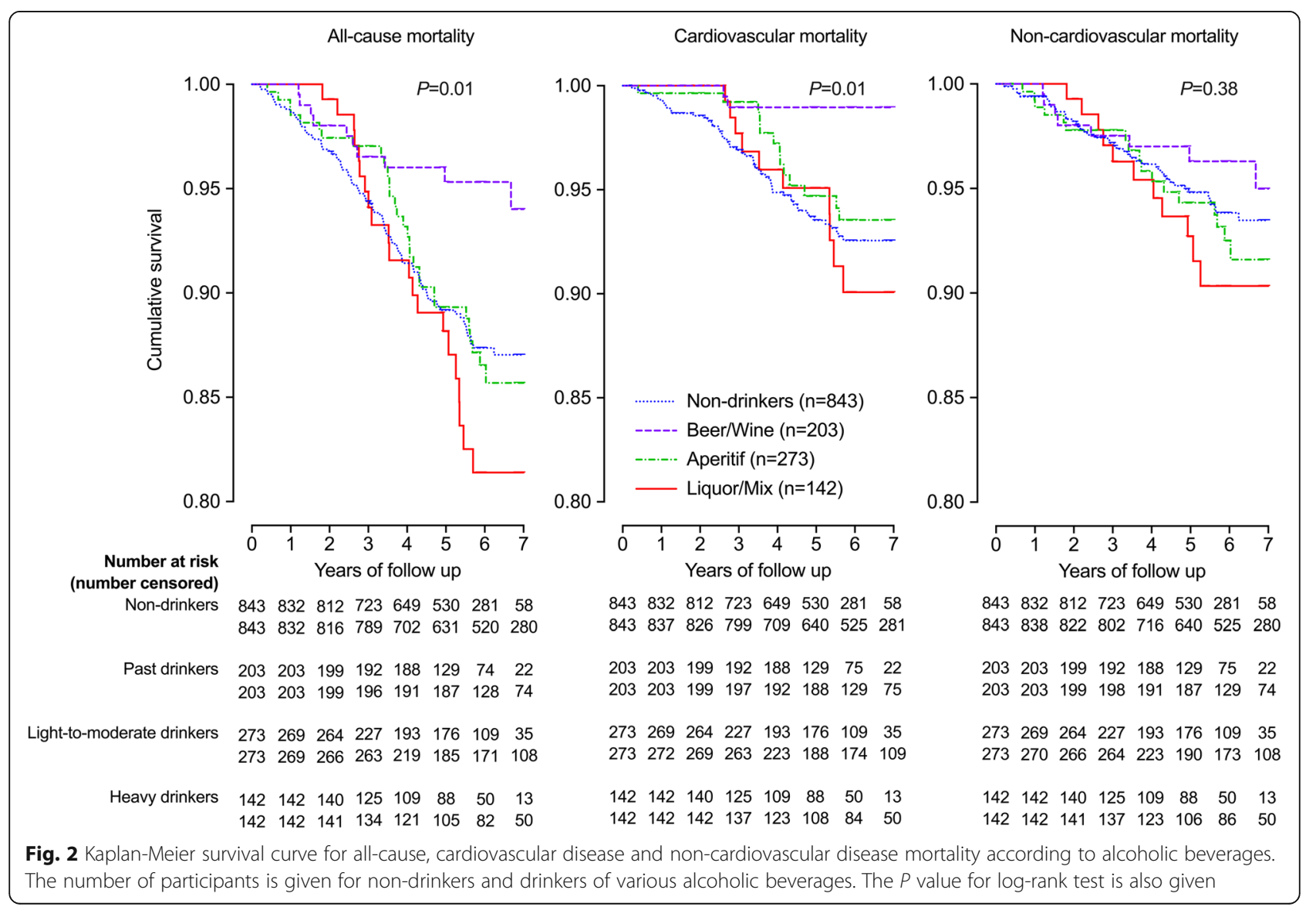


Table 3 All-cause, cardiovascular and non-cardiovascular mortality in relation to the type of alcoholic beverages

\begin{tabular}{|c|c|c|c|c|}
\hline & \multirow{2}{*}{$\begin{array}{l}\text { Non- } \\
\text { drinkers }\end{array}$} & \multicolumn{3}{|l|}{ Current drinkers } \\
\hline & & Beer/wine & Aperitif & Liquor/mix \\
\hline Number of participants & 843 & $147 / 56$ & 273 & 142 \\
\hline Number of person-years & 4429 & $834 / 319$ & 1424 & 748 \\
\hline Ethanol intake (g/week) & - & $210(182-420)$ & $504(252-630)$ & $600(280-840)$ \\
\hline \multicolumn{5}{|l|}{ All-cause mortality } \\
\hline Number of deaths & 100 & 10 & 30 & 21 \\
\hline Rate per 1000 person-years & 22.6 & 8.7 & 21.1 & 28.1 \\
\hline Age-adjusted HR (95\% Cl) & 1 & $0.53(0.28-1.02)$ & $1.04(0.69-1.57)$ & $1.52(0.95-2.44)$ \\
\hline Multivariate-adjusted HR (95\% Cl) & 1 & $0.53(0.27-1.06)$ & $1.00(0.60-1.67)$ & $1.50(0.82-2.72)$ \\
\hline \multicolumn{5}{|l|}{ Cardiovascular mortality } \\
\hline Number of deaths & 53 & 2 & 13 & 10 \\
\hline Rate per 1000 person-years & 12.0 & 1.7 & 9.1 & 13.4 \\
\hline Age-adjusted HR (95\% Cl) & 1 & $0.23(0.06-0.94)$ & $0.87(0.47-1.59)$ & $1.46(0.74-2.88)$ \\
\hline Multivariate-adjusted HR (95\% Cl) & 1 & $0.36(0.08-1.56)$ & $1.50(0.69-3.30)$ & $3.23(1.24-8.39)$ \\
\hline \multicolumn{5}{|l|}{ Non-cardiovascular mortality } \\
\hline Number of deaths & 47 & 8 & 17 & 11 \\
\hline Rate per 1000 person-years & 10.6 & 6.9 & 11.9 & 14.7 \\
\hline Age-adjusted HR (95\% Cl) & 1 & $0.80(0.38-1.70)$ & $1.22(0.70-2.12)$ & $1.59(0.82-3.06)$ \\
\hline Multivariate-adjusted HR (95\% Cl) & 1 & $0.71(0.32-1.56)$ & $0.90(0.46-1.77)$ & $1.23(0.58-2.64)$ \\
\hline
\end{tabular}

The multivariate analyses were adjusted for age, body-mass index, current smoking, serum total cholesterol and triglycerides, fasting plasma glucose, total alcohol consumption (ethanol intake per week) and the prevalence of hypertension and diabetes mellitus at baseline

Cl: confidence interval; HR: hazard ratio

drinkers tended to have a higher risk of mortality, especially when compared with beer/wine drinkers.

Our observation that past drinkers had a higher risk of all-cause mortality is in keeping with the results of several previous studies [13, 14]. In an American prospective study, past drinkers $(n=24,904)$ had a higher risk of all-cause (HR 1.35, 95\% CI 1.02-1.11) and cardiovascular (HR 1.27, 95\% CI 1.17-1.37) mortality than lifetime abstainers $(n=76,869)$ [13]. In a Spanish study, past drinkers $(n=432)$ also had a higher risk of all-cause mortality than never drinkers $(n=941)$ both before (HR $1.49,95 \%$ CI 1.03-2.14) and after exclusion of participants with functional limitations $(n=2665$, HR 1.68, 95\% CI 1.08-2.60) [14]. In the Prospective Urban Rural Epidemiology (PURE) study, however, past drinkers $(n=$ 4255), compared with never drinkers $(n=74,685)$, had a significantly higher risk of all-cause mortality (HR 1.56, 95\% CI 1.27-1.92) but non-significantly higher risk of fatal and nonfatal cardiovascular disease (HR 1.19, 95\%CI 0.94-1.50) [15]. In addition, the risk in 1207 past drinker versus 1076 never drinkers was not significantly higher either for all-cause (HR 1.13, 95\%CI 0.91-1.41) or cardiovascular mortality (HR 1.08, 95\%CI $0.77-1.53$ ) in a group of patients with a previous myocardial infarction, angina, or stroke enrolled in the UK Biobank Study
[16]. The risk of past drinking might have been confounded by the existence of severe diseases.

One of the possible mechanisms for the higher disease and mortality risk of past drinkers is that past drinkers often stopped alcohol intake because of illnesses or health concerns [17]. Indeed, in our present study, past drinkers, compared with non-drinkers and current drinkers, had a significantly higher prevalence of hypertension and use of antihypertensive drugs and a slightly higher prevalence of diabetes mellitus.

In line with the results of several recent studies [14, $18,19]$, our study did not show any beneficial effect of alcohol intake on cardiovascular disease mortality. In the abovementioned Spanish prospective study, neither light $(1.43-20 \mathrm{~g} / \mathrm{d}$ for men and $<10 \mathrm{~g} / \mathrm{d}$ for women, $n=785)$ nor moderate $(20-40 \mathrm{~g} / \mathrm{d}$ for men and $10-24 \mathrm{~g} / \mathrm{d}$ for women, $n=505$ ) drinkers had a lower risk of mortality than never drinkers [14]. However, these recent observations are in contradiction to the cardiovascular protective effects observed in several earlier previous studies [13, 20-22]. The latter observation might have been confounded by classifying past drinkers as abstainers. In a recent meta-analysis of 87 cohort studies $(n=$ 3,998,626), after controlling for abstainer bias, light drinking (1.3-24.9 g/day) did not show any protective 
effect on the risk of mortality (relative risk $0.97,95 \%$ CI $0.88-1.07$ ) [18]. Similarly, in a cohort study in 24,029 US adults aged more than 50 years, low level of moderate drinking ( $<7$ drinks/week) had a similar risk of all-cause mortality as occasional drinkers (HR 1.02, 95\% CI 0.941.11), whereas high level of moderate drinking ( 7 to $<14$ drinks/week) had a significantly higher risk of all-cause mortality than occasional drinkers (HR 1.14, 95\% CI 1.02-1.28) [19].

Abstaining might also have confounded the results of our study on the risks of heavy drinking. Heavy drinkers more likely stop drinking, because of illnesses or health concerns. In fact, current heavy drinkers had a higher systolic and diastolic blood pressure than non-drinkers, past drinkers and current light-to-moderate drinkers. The harmful effect of high blood pressure may appear with the longer-term follow-up.

Our observation on the lower risk of cardiovascular disease mortality in the current wine/beer drinkers is in accordance with the results of numerous previous studies [23-25]. Indeed, in a recent cohort study $(n=$ 114,970), wine (HR 0.88, 95\% CI 0.69-1.13) and beer drinkers (HR 0.86, 95\% CI 0.67-1.09), but not spirit or liquor drinkers (HR 0.97, 95\% CI 0.81-1.16), tended to have lower risks of all-cause mortality [15]. Our study only included a small number of wine drinkers $(n=56)$. The number of events in wine drinkers was small $(n=1)$ and does not allow analysis in beer and wine drinkers separately.

Our study should be interpreted within the context of its limitations. First, we only collected information on the amount and type of alcoholic beverages at baseline but not during follow-up. Second, the quantity of alcohol consumption was self-reported. Over- or underreporting is possible. Third, we did not collect information on the type of alcohol beverages or the lifetime drinking in past drinkers. We therefore were unable to perform analysis according to various alcoholic beverages and cumulative exposure to the risk in the past drinkers. Fourth, for the comparison between various alcoholic beverages, the number of events was small, leading to wide confidence intervals of the hazard ratios. Finally, because of the retrospective nature of the present analysis, sample size estimation was not performed prior to the analysis. Nonetheless, according to the observed proportion of alcohol intake, the present study may provide $84.9 \%$ of power to detect the observed association between alcohol intake and total mortality.

\section{Conclusions}

In summary, our study showed risks of mortality associated with past drinking and liquor drinking in men aged over 60 years of age in Shanghai, China. In fact, these two drinking factors are closely related. It is possible that high ethanol concentration of liquor drinking confers risks and when there are health concerns motivates abstaining from alcohol drinking. The latter hypothesis should be investigated in future studies of larger sample size and with information on the type of alcoholic beverages in past drinkers.

\section{Abbreviations \\ Cl: confidence interval; HR: hazard ratio}

\section{Acknowledgements}

We gratefully acknowledge the voluntary participation of all study subjects and the technical assistance of the physicians and nurses of Zhaoxiang Community Health Center (Qingpu District, Shanghai) and the expert assistance of Jie Wang, Li Zheng, Wei-Zhong Zhang, and Yi Zhou and of all master and PhD students who participated in the study during their study period.

\section{Availability of data and material}

The datasets analysed during the current study are not publicly available due to the privacy of individuals who participated in the study but are available from the corresponding author on reasonable request.

\section{Authors' contributions}

JGW contributed to the conception and design of the work. QFH, CSS, WZ and CYM conducted the data collection. XFY performed data analysis and prepared the first draft of the manuscript together with JGW. All authors critically revised the manuscript and gave the final approval.

\section{Funding}

The study investigators were financially supported by grants from the National Natural Science Foundation of China (91639203 and 82070435), Ministry of Science and Technology (grants 2015AA020105-06 and 2018YFC1704902), and Ministry of Health (grant 2016YFC0900902), Beijing, China, from the Shanghai Commissions of Science and Technology (grant 19DZ2340200), and Health (a special grant for "leading academics"), Shanghai, China, and from the Clinical Research Program, Ruijin Hospital, Shanghai Jiao Tong University School of Medicine (grant 2018CR010), Shanghai, China.

\section{Declarations}

Ethics approval and consent to participate

This study was approved by the Ethics Committee of Ruijin Hospital, Shanghai Jiao Tong University School of Medicine. All methods were performed in accordance with the relevant guidelines and regulations. Informed consent was obtained from all participants and also from legally authorized representatively of deceased participants.

Consent for publication

Not applicable.

\section{Competing interests}

Dr. Wang reports receiving lecture and consulting fees from Novartis, Omron, and Takeda. The other authors declared no conflicts of interest.

Received: 12 April 2021 Accepted: 29 October 2021

Published online: 09 November 2021

\section{References}

1. GBD 2016 Alcohol Collaborators. Alcohol use and burden for 195 countries and territories, 1990-2016: a systematic analysis for the Global Burden of Disease Study 2016. Lancet. 2018;392(10152):1015-35. https://doi.org/10.101 6/s0140-6736(18)31310-2.

2. World Health Organization. Global status report on alcohol and health 2018. World Health Organization.

3. Rumgay H, Shield K, Charvat H, Ferrari P, Sornpaisarn B, Obot I, et al. Global burden of cancer in 2020 attributable to alcohol consumption: a 
population-based study. Lancet Oncol. 2021;22(8):1071-80. https://doi.org/1 0.1016/S1470-2045(21)00279-5.

4. Millwood IY, Li L, Smith M, Guo Y, Yang L, Bian Z, et al. Alcohol consumption in 0.5 million people from 10 diverse regions of China: prevalence, patterns and socio-demographic and health-related correlates. Int J Epidemiol. 2013;42(3):816-27. https://doi.org/10.1093/ije/dyt078.

5. Im PK, Millwood IY, Guo Y, Du H, Chen Y, Bian Z, et al. Patterns and trends of alcohol consumption in rural and urban areas of China: findings from the China Kadoorie biobank. BMC Public Health. 2019;19(1):217. https://doi.org/1 0.1186/s12889-019-6502-1.

6. Sheng CS, Li Y, Huang QF, Kang YY, Li FK, Wang JG. Pulse waves in the lower extremities as a diagnostic tool of peripheral arterial disease and predictor of mortality in elderly Chinese. Hypertension. 2016;67(3):527-34. https://doi.org/10.1161/HYPERTENSIONAHA.115.06666.

7. Sheng CS, Li Y, Li LH, Huang QF, Zeng WF, Kang YY, et al. Brachial-ankle pulse wave velocity as a predictor of mortality in elderly Chinese. Hypertension. 2014;64(5):1124-30. https://doi.org/10.1161/HYPERTENSIONA HA.114.04063.

8. Sheng CS, Liu M, Zeng WF, Huang QF, Li Y, Wang JG. Four-limb blood pressure as predictors of mortality in elderly Chinese. Hypertension. 2013; 61(6):1155-60. https://doi.org/10.1161/HYPERTENSIONAHA.111.00969.

9. Sheng CS, Liu M, Kang YY, Wei FF, Zhang L, Li GL, et al. Prevalence, awareness, treatment and control of hypertension in elderly Chinese. Hypertens Res. 2013;36(9):824-8. https://doi.org/10.1038/hr.2013.57.

10. Li Y, Wang JG, Gao PJ, Wang GL, Qian YS, Zhu DL, et al. Interaction between body mass index and alcohol intake in relation to blood pressure in HAN and SHE Chinese. Am J Hypertens. 2006;19(5):448-53. https://doi.org/10.101 6/j.amjhyper.2005.08.014.

11. Cochrane J, Chen H, Conigrave KM, Hao W. Alcohol use in China. Alcohol Alcohol. 2003;38(6):537-42. https://doi.org/10.1093/alcalc/agg111.

12. Kleinbaum DG, Klein M. Survival Analysis. New York: Springer; 2005. p. 13172. https://doi.org/10.1007/0-387-29150-4.

13. Xi B, Veeranki SP, Zhao M, Ma C, Yan Y, Mi J. Relationship of alcohol consumption to all-cause, cardiovascular, and cancer-related mortality in U. S. adults. J Am Coll Cardiol. 2017;70(8):913-22. https://doi.org/10.1016/j.ja cc.2017.06.054.

14. Ortolá R, García-Esquinas E, López-García E, León-Muñoz LM, Banegas JR, Rodríguez-Artalejo F. Alcohol consumption and all-cause mortality in older adults in Spain: an analysis accounting for the main methodological issues. Addiction. 2019;114(1):59-68. https://doi.org/10.1111/add.14402.

15. Smyth A, Teo KK, Rangarajan S, O'Donnell M, Zhang X, Rana P, et al. Alcohol consumption and cardiovascular disease, cancer, injury, admission to hospital, and mortality: a prospective cohort study. Lancet. 2015;386(10007): 1945-54. https://doi.org/10.1016/s0140-6736(15)00235-4.

16. Ding C, O'Neill D, Bell S, Stamatakis E, Britton A. Association of alcohol consumption with morbidity and mortality in patients with cardiovascular disease: original data and meta-analysis of 48,423 men and women. BMC Med. 2021;19(1):167. https://doi.org/10.1186/s12916-021-02040-2.

17. Sarich P, Canfell K, Banks E, Paige E, Egger S, Joshy G, et al. A prospective study of health conditions related to alcohol consumption cessation among 97,852 drinkers aged 45 and over in Australia. Alcohol Clin Exp Res. 2019; 43(4):710-21. https://doi.org/10.1111/acer.13981.

18. Stockwell T, Zhao J, Panwar S, Roemer A, Naimi T, Chikritzhs T. Do "Moderate" drinkers have reduced mortality risk? A systematic review and meta-analysis of alcohol consumption and all-cause mortality. J Stud Alcohol Drugs. 2016;77(2):185-98. https://doi.org/10.15288/jsad.2016.77.185.

19. Goulden R. Moderate alcohol consumption is not associated with reduced all-cause mortality. Am J Med. 2016;129(2):180-6. https://doi.org/10.1016/j.a mimed.2015.10.013.

20. Kunzmann AT, Coleman HG, Huang WY, Berndt SI. The association of lifetime alcohol use with mortality and cancer risk in older adults: a cohort study. PLoS Med. 2018;15(6):e1002585. https://doi.org/10.1371/journal. pmed. 1002585.

21. Wood AM, Kaptoge S, Butterworth AS, Willeit P, Warnakula S, Bolton T, et al. Risk thresholds for alcohol consumption: combined analysis of individualparticipant data for 599912 current drinkers in 83 prospective studies. Lancet. 2018;391(10129):1513-23. https://doi.org/10.1016/S0140-6736(18)3 0134-X.

22. O'Keefe EL, DiNicolantonio JJ, O'Keefe JH, Lavie CJ. Alcohol and CV health: Jekyll and Hyde J-curves. Prog Cardiovasc Dis. 2018;61 (1):68-75. https://doi. org/10.1016/j.pcad.2018.02.001.
23. Renaud SC, Guéguen R, Siest G, Salamon R. Wine, beer, and mortality in middle-aged men from eastern France. Arch Intern Med. 1999;159(16):186570. https://doi.org/10.1001/archinte.159.16.1865.

24. Grønbaek M, Becker U, Johansen D, Gottschau A, Schnohr P, Hein HO, et al. Type of alcohol consumed and mortality from all causes, coronary heart disease, and cancer. Ann Intern Med. 2000;133(6):411-9. https://doi.org/10. 7326/0003-4819-133-6-200009190-00008.

25. Costanzo S, Di Castelnuovo A, Donati MB, lacoviello L, de Gaetano G. Wine, beer or spirit drinking in relation to fatal and non-fatal cardiovascular events: a meta-analysis. Eur J Epidemiol. 2011;26(11):833-50. https://doi. org/10.1007/s10654-011-9631-0.

\section{Publisher's Note}

Springer Nature remains neutral with regard to jurisdictional claims in published maps and institutional affiliations.
Ready to submit your research? Choose BMC and benefit from:

- fast, convenient online submission

- thorough peer review by experienced researchers in your field

- rapid publication on acceptance

- support for research data, including large and complex data types

- gold Open Access which fosters wider collaboration and increased citations

- maximum visibility for your research: over $100 \mathrm{M}$ website views per year

At BMC, research is always in progress.

Learn more biomedcentral.com/submissions 